BMJ Open

Diabetes

Research

\& Care

\title{
DIVE/DPV registries: benefits and risks of analog insulin use in individuals 75 years and older with type 2 diabetes mellitus
}

\author{
Gesine van Mark, ${ }^{1}$ Sascha R Tittel, ${ }^{2,3}$ Reinhard Welp, ${ }^{4}$ Jörg Gloyer, ${ }^{5}$ \\ Stefan Sziegoleit, ${ }^{6}$ Ralf Barion, ${ }^{7}$ Peter M Jehle, ${ }^{8}$ Dieter Erath, ${ }^{9}$ Peter Bramlage (D) , ${ }^{1}$ \\ Stefanie Lanzinger ${ }^{2,3}$
}

\begin{abstract}
To cite: van Mark G, Tittel SR, Welp R, et al. DIVE/DPV registries: benefits and risks of analog insulin use in individuals 75 years and older with type 2 diabetes mellitus. BMJ Open Diab Res Care 2021;9:e002215. doi:10.1136/ bmjdrc-2021-002215
\end{abstract}

Received 14 February 2021 Revised 24 March 2021 Accepted 28 March 2021
Check for updates

\section{(C) Author(s) (or their} employer(s)) 2021. Re-use permitted under CC BY-NC. No commercial re-use. See rights and permissions. Published by BMJ.

For numbered affiliations see end of article.

Correspondence to Professor Peter Bramlage; peter.bramlage@ippmed.de

\section{ABSTRACT}

Introduction The aims of this study were to

characterize insulin-treated individuals aged $\geq 75$ years with type 2 diabetes using basal insulin analogs (BIA) or regular insulins (human insulin $(\mathrm{HI}) /$ neutral protamine Hagedorn (NPH)) and to compare the benefits and risks. Research design and methods The analysis was based on data from the DPV (Diabetes-PatientenVerlaufsdokumentation) and DIVE (Dlabetes VersorgungsEvaluation) registries. To balance for confounders, propensity score matching for age, sex, diabetes duration, body mass index and hemoglobin A1c ( $\mathrm{HbA1c})$ as covariates was performed.

Results Among 167300 patients aged $\geq 75$ years with type 2 diabetes (mean age, 80.3 years), 9601 subjects used insulin regimens with basal insulin (HI/NPH or BIA). Of these 8022 propensity score-matched subjects were identified. The mean diabetes duration was $\sim 12$ years and half of the patients were male. At the time of switch, patients provided with BIA experienced more dyslipidemia ( $89.3 \%$ vs $85.9 \% ; p=0.002)$ and took a greater number of medications (4.3 vs $3.7 ; p<0.001)$ and depression was more prevalent ( $8.4 \%$ vs $6.5 \%$; $\mathrm{p}=0.01)$. Aggregated to the most actual treatment year, BIA was associated with a higher percentage of patients using basal-supported oral therapy $(42.6 \%$ vs $14.4 \%$ ) and intensified conventional insulin therapy (44.3\% vs $29.4 \%)$ and lower total daily insulin doses $(0.24 \mathrm{IU} / \mathrm{kg} /$ day vs $0.30 \mathrm{IU} / \mathrm{kg} /$ day; $p<0.001)$. The study did not reveal significant differences in efficacy (HbA1c $7.4 \%$ vs $7.3 \%$; $p=0.06)$, hospitalizations $(0.7$ vs 0.8 per patient-year (PY); $p=0.15)$, length of stay (16.3 vs 16.1 days per PY; $p=0.53$ ), or rates of severe hypoglycemia (4.07 vs 4.40 per $100 \mathrm{PY} ; \mathrm{p}=0.88$ ), hypoglycemia with coma (3.64 vs 3.26 per 100 PY; $\mathrm{p}=0.88)$ and diabetic ketoacidosis $(0.01$ vs 0.03 per 100 PY; $p=0.36$ ).

Conclusion BIA were used in more individually and patient-centered therapy regimens compared with HI/NPH in patients with a mean age of 80 years. Both groups were slightly overtreated with mean $\mathrm{HbA} 1 \mathrm{c}<7.5 \%$. The risk of severe hypoglycemia was low and independent of insulin type. Further analyses of elderly patients with type 2 diabetes are needed to provide evidence for best practice approaches in this age group.

\section{Significance of this study}

What is already known about this subject?

- Diabetes treatment in elderly patients is characterized by low hemoglobin $\mathrm{A} 1 \mathrm{c}(\mathrm{HbA1c})$ values and an increased risk of hypoglycemia.

What are the new findings?

$>$ Our study showed that there were few differences between regular insulins (human insulin/neutral protamine Hagedorn) and basal insulin analogs in terms of baseline patient characteristics and risk factors in patients aged $\geq 75$ years.

> Current guidelines advising a simple patientapproached therapy regimen to maintain selfmanagement abilities in the elderly were better reflected with insulin analogs.

$>$ Patients receiving both types of treatment were slightly overtreated with mean $\mathrm{HbA} 1 \mathrm{c}<7.5 \%$.

- The risk of severe hypoglycemia was low and was not associated with type of treatment.

How might these results change the focus of research or clinical practice?

- The findings of this study help to inform treatment of elderly patients with type 2 diabetes mellitus, although further research into diabetes treatments for this age group is needed.

\section{INTRODUCTION}

We previously described that type 2 diabetes (T2DM) treatment in elderly patients was characterized by rather low hemoglobin A1c (HbA1c) values, but an increased risk of hypoglycemia. ${ }^{12}$ Several studies show that elderly patients aged $>75$ years with T2DM are at increased risk of severe or fatal hypoglycemia and have higher hospitalization rates for hypoglycemic events. ${ }^{34}$

In contrast to neutral protamine Hagedorn (NPH) insulin, basal insulin analogs (BIA) showed a reduced risk of hypoglycemia in elderly and obese patients and in patients 
with renal impairment and cardiovascular disease (CVD). ${ }^{56}$ They have also been associated with reduced rates of nocturnal hypoglycemia, which is often unrecognized in the elderly. ${ }^{78}$ Further, long-acting insulin formulations can be used with a once daily dosing, providing sufficient glycemic control. ${ }^{9}$

Contrary to what we would have expected on the background of elderly patients and treatment characteristics, the elderly were treated more frequently with regular human insulin (HI) (from $35.0 \%$ of those aged 70-79 years old to $37.9 \%$ of those aged $\geq 90$ years old) than with BIA (from $29.7 \%$ of those aged $70-79$ years old to $23.5 \%$ of those aged $\geq 90$ years old) in our previous study. This is unlike a global trend in diabetes treatment where insulin analogs are increasingly being used in a general diabetes patient population. ${ }^{10}$

To explore the determinants and potential benefits of use of basal insulin in these elderly patients with T2DM, we had a closer look at patients who were at least 75 years of age and were receiving either basal HI/ NPH insulin and compared the treatment outcomes with patients receiving BIA. We used propensity score matching in order to balance the characteristics of the patients at the time of switch to insulin (baseline). Our study aimed to address the following specific questions: (1) Do baseline patient characteristics, risk factors and comorbidities differ by type of insulin treatment? (2) Do concomitant antidiabetic drugs differ in relation to the basal insulin used? (3) Do efficacy parameters (eg, HbAlc, fasting blood glucose (FBG) and insulin dose) differ by type of insulin treatment? (4) Do safety parameters (eg, number of hospitalizations, mean length of stay, risk of hypoglycemia and hypoglycemia with coma, diabetic ketoacidosis (DKA)) differ by type of insulin treatment?

\section{RESEARCH DESIGN AND METHODS \\ Data collection}

Prospective longitudinal, standardized routine data were obtained from the prospective, multicenter German patient databases on diabetes mellitus: DPV (DiabetesPatienten-Verlaufsdokumentation) and DIVE (DIabetes Versorgungs-Evaluation).

DPV data on patients with diabetes mellitus are collected during routine examinations using DPV software and the anonymized data are sent to Ulm University for inclusion into the database every 6 months. Detailed information on the documentation systems has been published previously. ${ }^{10}{ }^{11}$ This analysis includes data from 159 DPV centers.

The DIVE registry was established in Germany in 2011. ${ }^{12}$ Consecutive patient data are collected from German centers and these patients continue to be followed up. Data are entered into an online database using DPV software. All patients provided written informed consent. This study comprises data of 101 DIVE study sites.

\section{Patient population for the analysis}

Patients were sampled in September 2020 and were included in the current analysis if they had at least one clinic visit per year and their documented therapy was available. We selected patients of at least 75 years with T2DM with basal insulin (human or analog) or NPH insulin treatment. Patients aged $<75$ years, with other forms of diabetes, using an insulin pump or with prandial insulin only were excluded. The final study comprised 8022 propensity score-matched (PSM) subjects for baseline and 3836 PSM subjects for follow-up analysis. The mean follow-up period was $2.3 \pm 2.1$ years for the HI/NPH group and 2.6 \pm 2.1 years for BIA.

\section{Definitions}

Hypertension was defined as $\geq 145 \mathrm{~mm} \mathrm{Hg}$ for systolic blood pressure and/or a diastolic blood pressure of $\geq 85$ $\mathrm{mm} \mathrm{Hg}$ and/or antihypertensive treatment. ${ }^{1314}$ Body mass index (BMI) was defined as bodyweight divided by the square body height in $\mathrm{kg} / \mathrm{m}^{2}$. Dyslipidemia was defined as a low-density lipoprotein cholesterol of $\geq 100 \mathrm{mg}$ / $\mathrm{dL}(\geq 2.6 \mathrm{mmol} / \mathrm{L})$ without further risk factors and $\geq 70$ $\mathrm{mg} / \mathrm{dL}(\geq 1.8 \mathrm{mmol} / \mathrm{L})$ in patients with CVD or chronic kidney disease or those receiving lipid-lowering drug treatment. ${ }^{1315}$ Comorbidities were grouped into (patientreported or physician-reported) microvascular and macrovascular diseases. The former included any form of retinopathy, blindness, nephropathy, renal failure, dialysis or neuropathy. The latter included transient ischemic attack/prolonged reversible ischemic neurologic deficit, stroke, coronary artery disease, myocardial infarction and peripheral arterial disease. Polypharmacy was determined as a numerical-only definition of $>10$ medications that were used concomitantly. ${ }^{16}$ The DIVE/ DPV databases were searched with focus on drug categories according to the PRISCUS listing. ${ }^{17}$ Medications comprised prescription medications and routine use of over-the-counter medications.

HbA1c values were standardized to the Diabetes Control and Complications Trial. ${ }^{18}{ }^{19}$ For severe hypoglycemia, the definition of the American Diabetes Association Workgroup on Hypoglycemia ('an event requiring assistance by another person to actively administer carbohydrates, glucagon or other resuscitative actions') was applied. ${ }^{20}$ Hypoglycemia with coma was defined as loss of consciousness or occurrence of seizures. ${ }^{10}$ DKA was defined as $\mathrm{pH}<7.3$ and/or bicarbonate $<15 \mathrm{mmol} / \mathrm{mol}$ or hospitalization for DKA. Insulin regimen was categorized as follows: (1) basalsupported oral therapy (BOT) (basal insulin only); (2) supplementary insulin therapy (SIT) (prandial insulin only); (3) conventional insulin therapy (CT) (prandial and basal insulin combined, up to three injection time points); (4) intensified conventional insulin therapy (ICT) (prandial and basal insulin combined, $>3$ injection time points); and (5) continuous subcutaneous insulin infusion (CSII). ${ }^{10}$ To stratify patients using basal insulin, patients on SIT and CSII were 
excluded. Patients on BOT, CT or ICT were identified because these therapy regimens use a long-acting (basal) insulin or premixed/co-formulation insulin. Patients on basal insulin were divided by use of $\mathrm{HI}$ / $\mathrm{NPH}$ and BIA. Insulin treatment initiation had to be documented between 2000 and June 2020, with HbA1c and BMI data available \pm 3 months from the time of insulin initiation. Baseline data for patients were aggregated within \pm 3 months of insulin initiation. Follow-up data were aggregated to the most recent documented treatment year without therapy switch (excluding the baseline period). Treatment was considered continuous if there was a maximum gap of 120 days between two clinic visits, with the same treatment being documented before and after the gap.

\section{Statistics}

Data from the two registries were combined and analyzed as a single data set. Data were then aggregated as medians in the year of intensification with insulin (baseline). Categorical variables are presented as percentages and continuous variables are presented as mean \pm SD. Rates and event rates are presented per 100 patient-years (PY). Differences of non-PSM variables were analyzed using Wilcoxon test for continuous variables or $\chi^{2}$ test for binary variables. $\mathrm{P}$ values were adjusted for multiple testing using the Bonferroni stepdown method.

Propensity score matching was used to ensure that both the HI/NPH therapy regimen group and the BIA group had similar baseline characteristics. Differences between the treatment groups and propensity score for insulin analogs were estimated according to a former analyses of the DIVE/DPV registries. ${ }^{21}$ The multivariable logistic regression model includes age, sex, duration of diabetes, BMI and HbAlc level as covariates. For each patient, the probability (propensity score) for $\mathrm{HI} / \mathrm{NPH}$ and BIA was estimated from the logistic model based on the patient's specific covariate values. Matching was conducted with a one-to-one matching process (greedy-matching algorithm) and caliper width 0.2 . To evaluate balancing of matched variables, standardized differences were assessed. A standardized difference of $<10 \%$ indicates a negligible difference in the mean. ${ }^{22}$ In order to compare hospitalization times and lengths of stay between the matched groups, a standard Poisson regression model with the logarithm of the individual time under risk as offset was used. Event rates of severe hypoglycemia, hypoglycemic coma, DKA and severe DKA were calculated and compared using negative binomial regression with the logarithm of the individual time under risk as offset. For HbA1c a linear regression model was used. Further, incidence rate ratios and 95\% CIs were calculated for DKA, hypoglycemia and hypoglycemia with coma.

A p value $<0.05$ was considered statistically significant. Statistical analysis was performed using SAS V.9.4.
RESULTS

\section{Patient population}

The DIVE/DPV registries included 167300 patients with T2DM aged $\geq 75$ years at the time of data export. Of these, $29800(17.8 \%)$ patients initiated insulin therapy between 2000 and June 2020, and 11108 (6.6\%) used therapy regimens with basal insulin. The final analysis comprised 9601 patients in the entire cohort $(n=5583$ on regular insulin and $n=4018$ on insulin analogs) and 8022 PSM patients $(n=4011$ in both treatment groups) (figure 1).

\section{Patient baseline characteristics}

For analysis of baseline characteristics 4011 matched pairs were available. The standardized differences for the matched variables were highest for HbA1c $(4.5 \%$ for the entire cohort and $2.0 \%$ for the matched cohort) and age $(-6.1 \%$ and $0.6 \%)$ but remained largely under $10 \%$, demonstrating a negligible difference between both treatment groups (table 1 ). The mean patient age was 80.3 years in both matched treatment groups, half of the patients were male, the mean diabetes duration was approximately 12 years, and the mean baseline HbAlc was $8.6 \%$ for both insulins. There were only minor significant differences in the entire cohort as well as in the matched cohort for non-matched variables at time of insulin therapy initiation.

FBG did not differ between the groups $(10.6 \mathrm{mmol} / \mathrm{L}$ vs $10.7 \mathrm{mmol} / \mathrm{L}, \mathrm{p}=0.50$ for the entire cohort; 10.6 $\mathrm{mmol} / \mathrm{L}$ vs $10.8 \mathrm{mmol} / \mathrm{L}$ for the PMS cohort, $\mathrm{p}=0.42$ ). The bodyweight of BIA patients in the entire cohort was slightly higher (79.4 kg vs $80.6 \mathrm{~kg}$; $\mathrm{p}=0.003)$, but this difference was not seen in the PMS cohort $(80.2 \%$ vs $80.6 \% ; \mathrm{p}=1.00)$. In the PMS cohort, the proportion of patients with dyslipidemia was higher in the BIA group (85.9\% vs $89.3 \%$; $\mathrm{p}=0.001)$. The proportions of other risk factors such as hypertension $(71.0 \%$ vs $73.5 \%)$ and smoking $(3.5 \%$ vs $3.4 \%)$ were largely similar. The only exception was the mean number of medications, which was significantly higher in the BIA group compared with the HI/NPH group in (both cohorts 3.7 vs 4.3; p<0.001), whereas the proportion of patients with polypharmacy was borderline significantly lower in the HI/NPH group of the entire cohort $(0.5 \%$ vs $1.1 \% ; \mathrm{p}=0.05)$, but not in the matched cohort $(0.6 \%$ vs $1.1 \% ; \mathrm{p}=0.26)$. Furthermore, in the PSM cohort depression was more prevalent with BIA treatment $(6.5 \%$ vs $8.4 \%$; $\mathrm{p}=0.01)$.

There were small differences in the prevalence of comorbidities such as dementia (HI/NPH $7.9 \%$ vs BIA $8.8 \%$ ), cancer (HI/NPH $5.0 \%$ vs BIA $5.8 \%$ ) and microvascular and macrovascular diseases $(\mathrm{HI} / \mathrm{NPH} 85.3 \%$ vs BIA $83.6 \%$ and $\mathrm{HI} / \mathrm{NPH} 44.6 \%$ vs BIA $44.4 \%$ ), but these were not statistically significant.

The proportion of care-dependent patients (HI/NPH $5.2 \%$ vs BIA $7.1 \%$ ) was low and there were no differences observed between both treatment groups. Marginally more than one-third of the patients participated in a diabetes management program (HI/NPH $37.1 \%$ vs BIA $37.9 \%$ ). 


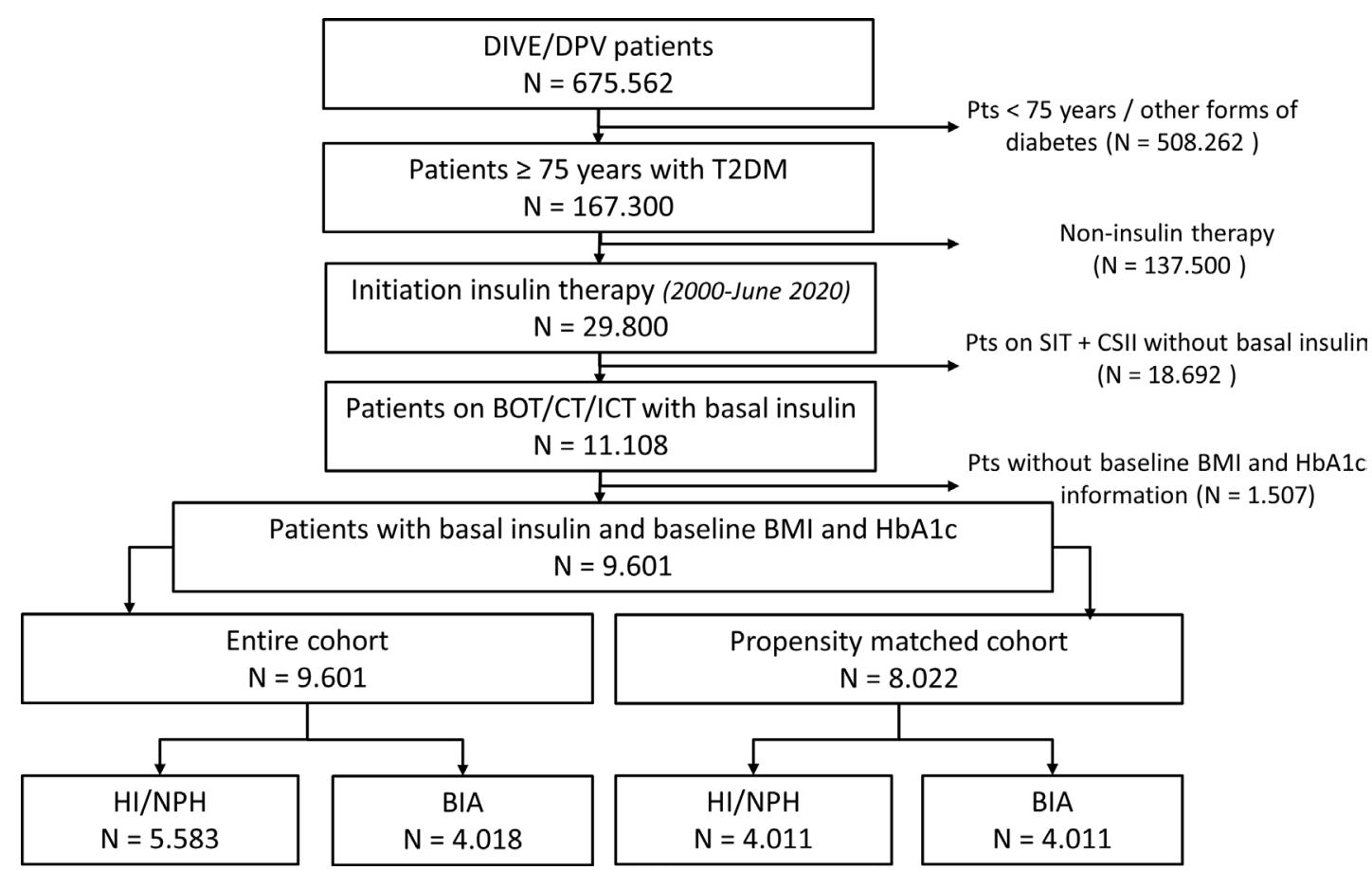

Figure 1 Patient flow. BIA, basal insulin analog; BMI, body mass index; BOT, basal-supported oral therapy: basal insulin only; CSII, continuous subcutaneous insulin infusion (insulin pump); CT, conventional insulin therapy, prandial and basal insulin combined (up to three injection time points); DIVE, Dlabetes Versorgungs-Evaluation; DPV, Diabetes-PatientenVerlaufsdokumentation; HbA1c, hemoglobin A1c; HI, human insulin; ICT, intensified conventional insulin therapy, prandial and basal insulin combined (>3 injection time points); n, patient number; NPH, neutral protamine Hagedorn; pts, patients; SIT, supplementary insulin therapy (prandial insulin only); T2DM, type 2 diabetes.

\section{Concomitant antidiabetic drugs at follow-up}

Detailed information on concomitant antidiabetic treatment was available for $49.5 \%$ of the $\mathrm{HI} / \mathrm{NPH}$ subjects and $46.1 \%$ of the BIA group for the most recent treatment year (follow-up) (table 2). Most of the patients on regular insulin were treated with CT $(56.2 \%$ vs $13.2 \%$; $\mathrm{p}<0.001)$, whereas BOT and ICT were more frequent with BIA ( $14.4 \%$ vs $42.6 \%$ and $29.4 \%$ vs $44.3 \%$; both $\mathrm{p}<0.001)$.

Rapid-acting insulin was added to basal insulin concomitantly in $79.4 \%$ of $\mathrm{HI} / \mathrm{NPH}$ and $53.5 \%$ of BIA patients. Rapid-acting HI was preferred in the HI/NPH group versus the BIA group $(61.3 \%$ vs $19.3 \%)$. The reverse was true for rapid-acting analogs $(18.1 \%$ vs $34.1 \%)$ (both $\mathrm{p}<0.001)$.

Oral antidiabetic drugs and glucagon-like peptide-1 (GLP-1) agonists were more frequently used in patients using insulin analogs. Usage proportions were highest for metformin (23.3\% vs $28.7 \%$ ), dipeptidyl peptidase- 4 (DPP-4) inhibitors $(10.0 \%$ vs $25.8 \%)$ and sulfonylureas $(10.8 \%$ vs $11.2 \%)$. With the exception of the latter and glucosidase inhibitors, differences in non-insulin antidiabetic therapy were highly significant between both groups. However, percentages of patients taking glucosidase inhibitors $(0.8 \%$ vs $0.9 \%)$, GLP agonists $(0.8 \%$ vs $2.2 \%$ ) and sodium/glucose cotransporter 2 (SGLT-2) inhibitors $(0.6 \%$ vs $3.6 \%)$ were low.

\section{Efficacy and safety parameters}

A comparison of follow-up data in 1984 matched patients on $\mathrm{HI} / \mathrm{NPH}$ to 1852 patients on insulin analog was used to determine differences in glycemic control, rates of severe hypoglycemia and DKA (table 3 ).

\section{Glycemic control and hospitalizations}

Patients in the BIA group needed less total daily insulin $(0.30 \mathrm{IU} / \mathrm{kg} /$ day vs $0.22 \mathrm{IU} / \mathrm{kg} /$ day; $\mathrm{p}<0.001)$. The prandial to total insulin ratio was higher in the BIA group compared with the regular insulin group ( 0.83 vs $0.70 ; \mathrm{p}<0.001)$, demonstrating a higher use of prandial insulin in the BIA group. The resulting median HbA1c was similar with $\mathrm{HI} / \mathrm{NPH}$ treatment and BIA treatment ( $7.3 \%$ vs $7.4 \%$; $=0.06$ ). FBG did not differ between the groups (both $8.4 \mathrm{mmol} / \mathrm{L} ; \mathrm{p}=0.85$ ).

The mean number of hospitalizations per PY was slightly lower in the BIA compared with the HI/NPH group, but did not reach statistical significance $(0.7$ vs $0.8 ; p=0.15)$. The mean length of stay per PY did not differ between the groups (HI/NPH 16.1 days vs BIA 16.3 days; $\mathrm{p}=0.53$ ).

\section{Hypoglycemia and DKA}

Of the $\mathrm{HI} / \mathrm{NPH}$ patients $48.6 \%$ had HbA1c values below the median HbAlc and no severe hypoglycemia or hypoglycemia with coma was observed. The same was true for $51.5 \%$ of the BIA group ( $\mathrm{p}=0.09 \mathrm{HI} / \mathrm{NPH}$ vs BIA). Overall, $2.8 \%$ of subjects on regular insulin and $2.4 \%$ on insulin analogs suffered at least one severe hypoglycemia event. Event rates for severe hypoglycemia, however, tended to be lower in the BIA group but did not reach statistical significance (HI/NPH 4.4 and BIA 4.1 per 100 PY; $\mathrm{p}=0.88$ ). Severe hypoglycemia with coma was 
Table 1 Characteristics of patients aged $>75$ years with HI/NPH vs BIA at baseline

\begin{tabular}{|c|c|c|c|c|c|c|}
\hline & \multicolumn{6}{|c|}{ Propensity-matched variables at baseline } \\
\hline & \multicolumn{3}{|c|}{ Entire cohort } & \multicolumn{3}{|c|}{ PS-matched cohort } \\
\hline & $\begin{array}{l}\text { HI/NPH } \\
n=5583\end{array}$ & $\begin{array}{l}B \mid A \\
n=4018\end{array}$ & $\begin{array}{l}\text { Standardized } \\
\text { difference, \% }\end{array}$ & $\begin{array}{l}\text { HI/NPH } \\
n=4011\end{array}$ & $\begin{array}{l}B \mid A \\
n=4011\end{array}$ & $\begin{array}{l}\text { Standardized } \\
\text { difference, \% }\end{array}$ \\
\hline Age, years & $80.6 \pm 4.2$ & $80.3 \pm 4.2$ & -6.1 & $80.3 \pm 4.1$ & $80.3 \pm 4.1$ & 0.6 \\
\hline Male, \% & 40.0 & 50.0 & -5.7 & 47.0 & 50.0 & 0.0 \\
\hline $\mathrm{HbA1c}, \%$ & $8.5 \pm 2.1$ & $8.6 \pm 2.1$ & 4.5 & $8.6 \pm 2.2$ & $8.6 \pm 2.1$ & 2.0 \\
\hline \multirow[t]{2}{*}{$\mathrm{HbA} 1 \mathrm{c}, \mathrm{mmol} / \mathrm{mol}$} & $69.9 \pm 23.4$ & $71.0 \pm 23.4$ & & $70.4 \pm 23.5$ & $70.9 \pm 23.2$ & \\
\hline & \multicolumn{6}{|c|}{ Other variables at baseline } \\
\hline Bodyweight, kg & $79.4 \pm 15.9$ & $80.6 \pm 16.3$ & 0.003 & $80.2 \pm 15.9$ & $80.6 \pm 16.2$ & 1.000 \\
\hline FBG, mmol & $10.6 \pm 5.9$ & $10.7 \pm 5.6$ & 0.496 & $10.6 \pm 5.9$ & $10.8 \pm 5.6$ & 0.423 \\
\hline \multicolumn{7}{|l|}{ Risk factors } \\
\hline $\begin{array}{l}\text { Number of } \\
\text { medications, } \mathrm{n}\end{array}$ & $3.7 \pm 2.3$ & $4.3 \pm 2.5$ & $<0.001$ & $3.7 \pm 2.3$ & $4.3 \pm 2.5$ & $<0.001$ \\
\hline Hypertension, \% & 71.2 & 73.5 & 0.100 & 71.0 & 73.5 & 0.125 \\
\hline $\mathrm{BMI}>30 \mathrm{~kg} / \mathrm{m}^{2}, \%$ & 36.1 & 37.9 & 0.496 & 37.6 & 37.8 & 1.000 \\
\hline Dyslipidemia,\% & 86.0 & 89.3 & $<0.001$ & 85.9 & 89.3 & 0.001 \\
\hline Smokers, \% & 3.6 & 3.4 & 1.000 & 3.5 & 3.4 & 1.000 \\
\hline \multicolumn{7}{|l|}{ Mental status, \% } \\
\hline Dementia & 8.0 & 8.8 & 0.827 & 7.9 & 8.8 & 1.000 \\
\hline Depression & 6.6 & 8.4 & 0.007 & 6.5 & 8.4 & 0.014 \\
\hline \multicolumn{7}{|l|}{ Comorbidities, \% } \\
\hline Cancer & 5.0 & 5.8 & 0.809 & 5.0 & 5.8 & 1.000 \\
\hline $\begin{array}{l}\text { Microvascular } \\
\text { disease* }^{*}\end{array}$ & 85.2 & 83.6 & 0.225 & 85.3 & 83.6 & 0.352 \\
\hline $\begin{array}{l}\text { Macrovascular } \\
\text { disease } †\end{array}$ & 44.5 & 44.3 & 1.000 & 44.6 & 44.4 & 1.000 \\
\hline
\end{tabular}

Data are presented as mean \pm SD or $\%$.

Bold numbers indicate $p$-values $<0.05$.

*Includes any form of retinopathy, blindness, nephropathy, renal failure, dialysis or neuropathy.

†Includes transient ischemic attack/prolonged reversible ischemic neurologic deficit, stroke, coronary heart disease, myocardial infarction and peripheral arterial disease.

BIA, basal insulin analog; BMI, body mass index; FBG, fasting blood glucose; HbA1c, hemoglobin A1c; HI, human insulin; NPH, neutral protamine Hagedorn; PS, propensity score.

documented in DPV only and observed in $2.8 \%$ of the $\mathrm{HI} / \mathrm{NPH}$ group and $3.0 \%$ of the BIA group with event rates of 3.3 and 3.6 per $100 \mathrm{PY}(\mathrm{p}=0.88)$. The percentage of patients with DKA was low and the event rates did not differ $(\mathrm{HI} / \mathrm{NPH} 0.3 \%$ vs $0.1 \%$ of patients and 0.28 vs 0.05 per $100 \mathrm{PY}$; $\mathrm{p}=0.36)$. 
Table 2 Antidiabetic treatment in patients aged $>75$ years with regular vs analog insulin (follow-up)

\begin{tabular}{|c|c|c|c|}
\hline & $\begin{array}{l}\text { HI/NPH } \\
n=1984\end{array}$ & $\begin{array}{l}\text { BIA } \\
n=1852\end{array}$ & $P$ value \\
\hline \multicolumn{4}{|c|}{ Insulin treatment strategy, \% } \\
\hline BOT & 14.4 & 42.6 & $<0.001$ \\
\hline CT & 56.2 & 13.2 & $<0.001$ \\
\hline ICT & 29.4 & 44.3 & $<0.001$ \\
\hline $\begin{array}{l}\text { Rapid-acting } \\
\text { insulin, \% }\end{array}$ & 79.4 & 53.5 & $<0.001$ \\
\hline Human & 61.3 & 19.3 & $<0.001$ \\
\hline Analogs & 18.1 & 34.1 & $<0.001$ \\
\hline \multicolumn{4}{|c|}{ Non-insulin antidiabetic treatment, \% } \\
\hline Metformin & 23.3 & 28.7 & $<0.001$ \\
\hline Sulfonylurea & 10.8 & 11.2 & 1.000 \\
\hline $\begin{array}{l}\text { Glucosidase } \\
\text { inhibitors }\end{array}$ & 0.8 & 0.9 & 1.000 \\
\hline Glinides & 3.7 & 6.1 & 0.002 \\
\hline DPP-4 inhibitor & 10.0 & 25.8 & $<0.001$ \\
\hline GLP-1 agonist & 0.8 & 2.2 & 0.001 \\
\hline SGLT-2 inhibitor & 0.6 & 3.6 & $<0.001$ \\
\hline
\end{tabular}

CT: prandial and basal insulin combined (up to 3 injection time points); ICT: prandial and basal insulin combined ( $>3$ injection time points).

Bold numbers indicate $p$-values $<0.05$.

BIA, basal insulin analog; BOT, basal insulin-supported oral therapy: basal insulin only; CT, conventional insulin therapy; DPP-4, dipeptidyl peptidase-4; GLP-1, glucagon-like peptide-1; $\mathrm{HI}$, human insulin; ICT, intensified conventional insulin therapy; $\mathrm{NPH}$, neutral protamine Hagedorn; SGLT-2, sodium/glucose cotransporter 2.

Incidence rate ratios and $95 \%$ CIs show no differences in risk of severe hypoglycemia $(0.95,95 \%$ CI 0.34 to 2.61), hyperglycemic events with coma $(1.16,95 \%$ CI 0.25 to 5.27$)$ and DKA $(0.19,95 \%$ CI 0.01 to 6.80$)$ between regular insulins compared with insulin analogs (figure 2).

\section{DISCUSSION}

The aims of this analysis were to describe the characteristics of a large cohort of almost 10000 patients aged $\geq 75$ years with T2DM and to compare efficacy and safety parameters with different insulin therapies. This analysis focused on the benefits (eg, HbAlc) and risks (severe hypoglycemia and DKA) of basal insulin therapy with NPH and/or HI compared with insulin analogs. To our knowledge, this is the first study comparing regular insulin and insulin analogs in a population of patients with T2DM with a mean age of 80 years.

At the time of switching to insulin, patients prescribed BIA had a worse metabolic profile, took a greater number of medications and were at higher risk of depression compared with patients prescribed HI/NPH. Furthermore, prescription of BIA was associated with more individually and patient-centered therapy regimens like BOT and ICT and lower total daily insulin doses. The study described an improvement in HbAlc control with insulin therapy for both insulin treatments, but did not reveal any significant differences in efficacy or safety with regard to type of insulin.

\section{Patient population}

Patients with BIA tended to have more risk factors at baseline. This became significant in the slightly higher number of medications taken (4.3 vs 3.7) and higher proportion of patients with dyslipidemia in the BIA group. Although lipid targets are more likely to be met in the elderly, it is assumed that diabetic dyslipidemia in the elderly is undertreated. ${ }^{23}{ }^{24}$ T2DM and obesity are also linked with depression, ${ }^{25}$ which also was more prevalent in the BIA group. Interestingly, the proportion of patients with polypharmacy (defined in this study as $>10$ medications) was only $0.6 \%$ and $1.1 \%$ in the $\mathrm{HI} / \mathrm{NPH}$ and BIA groups, respectively. Although some medications are documented only in the DPV registry and not in DIVE, data indicate that this risk factor plays a minor role in the patient population.

Among the insulin-treated patients in this study the proportion of patients with hypertension was high $(71.0 \%$ for $\mathrm{HI} / \mathrm{NPH}$ and $73.5 \%$ for BIA). The dysregulation of neurohumoral and neuroimmune pathways contributes to the pathophysiology of both T2DM and hypertension; thus, there is a bidirectional association between macrovascular and microvascular systems. ${ }^{26}$ In line with this, we observed in this insulin-treated population a higher proportion of microvascular disease $(85.3 \%$ vs $83.6 \%)$ compared with our previous DIVE/DPV analysis (also including insulin-naïve subjects), which revealed proportions from $59.8 \%$ of patients aged $70-79$ years old to $50.4 \%$ of those aged $>90$ years. $^{2}$

In Germany care-dependent elderly live either at home (assisted by family, caregivers or home care providers) or in 'shared housing arrangements' and nursing homes. ${ }^{27}$ The prevalence of care dependency rises from $8 \%$ among those aged 75-79 years old to $76 \%$ among those aged $>90$ years old. ${ }^{28}$ Surprisingly, in our study only $5.2 \%$ and $5.5 \%$ of patients with T2DM at comparable age were care-dependent. A previous study reported that care-dependent patients with T2DM are more likely to be treated with insulin compared with independent patients. ${ }^{29}$ However, a large proportion of nursing home residents are treated by general practitioners and not diabetologists and are therefore probably not documented in the registries. ${ }^{29}$ Furthermore, the support of self-management and therapy adherence and the intensified lifestyle training (eg, 37\% of patients included in disease management programs) may lead to a higher proportion of independent elderly patients compared with the above-mentioned German statistics. $^{28}$ 
Table 3 Glycemic control and safety parameters in patients aged $>75$ years with HI/NPH vs insulin analogs (follow-up)

\begin{tabular}{|c|c|c|c|}
\hline & $\begin{array}{l}\mathrm{HI} / \mathrm{NPH} \\
\mathrm{n}=1.984\end{array}$ & $\begin{array}{l}\text { BIA } \\
n=1.852\end{array}$ & $P$ value \\
\hline $\mathrm{HbA1c} \%$ & 7.3 (7.25 to 7.36$)$ & 7.4 (7.32 to 7.42$)$ & 0.057 \\
\hline $\mathrm{HbA} 1 \mathrm{c}, \mathrm{mmol} / \mathrm{mol}$ & 56.3 (55.7 to 56.9$)$ & 57.1 (56.5 to 57.7$)$ & 0.057 \\
\hline Fasting blood glucose, $\mathrm{mmol} / \mathrm{L}$ & $8.4(8.2$ to 8.6$)$ & $8.4(8.3$ to 8.6$)$ & 0.849 \\
\hline Total daily insulin dose, IU/kg/day & $0.296(0.281$ to 0.311$)$ & 0.239 (0.224 to 0.254$)$ & $<0.001$ \\
\hline Prandial to total insulin ratio, $\%$ & 70.07 (71.59 to 98.52$)$ & 82.76 (39.63 to 74.17 ) & $<0.001$ \\
\hline Hospitalization per patient-year, $n$ & $0.8(0.7$ to 0.9$)$ & $0.7(0.7$ to 0.8$)$ & 0.145 \\
\hline Length of stay per patient-year, days & $16.1(15.7$ to 16.5$)$ & $16.3(15.8$ to 16.7$)$ & 0.533 \\
\hline $\begin{array}{l}<\mathrm{HbA} 1 \mathrm{c} \text { median and no severe } \\
\text { hypoglycemia* or hypoglycemia with } \\
\text { comat, \% of patients }\end{array}$ & 48.6 & 51.5 & 0.086 \\
\hline \multicolumn{4}{|l|}{ Severe hypoglycemia* } \\
\hline Patients with events, \% & 2.8 & 2.4 & \\
\hline Rate per 100 patient-years & 4.40 (2.2 to 8.8$)$ & 4.07 (2.0 to 8.8$)$ & 0.881 \\
\hline \multicolumn{4}{|l|}{ Hypoglycemic coma† } \\
\hline Patients with events, \% & 2.8 & 3.0 & \\
\hline Rate per 100 patient-years & 3.26 (1.2 to 9.0$)$ & 3.64 (1.2 to 10.8$)$ & 0.885 \\
\hline \multicolumn{4}{|l|}{ Diabetic ketoacidosis $\ddagger$} \\
\hline Patients with events, \% & 0.3 & 0.1 & \\
\hline Rate per 100 patient-years & 0.28 (0.02 to 3.37$)$ & 0.05 (0.04 to 0.7$)$ & 0.363 \\
\hline
\end{tabular}

Data shown as LS mean $(95 \% \mathrm{CI})$.

Bold numbers indicate $p$-values $<0.05$.

${ }^{*}$ Defined as an event requiring assistance by another person to actively administer carbohydrates, glucagon or other resuscitative actions.

†Defined as loss of consciousness or occurrence of seizures.

†Defined as $\mathrm{pH}<7.3$ and/or bicarbonate $<15 \mathrm{mmol} / \mathrm{mol}$ or hospitalization for diabetic ketoacidosis.

$\mathrm{BIA}$, basal insulin analogs; HbA1c, hemoglobin A1c; HI, human insulin; IU, international unit; LS, least squares means; NPH, neutral protamine Hagedorn.

\section{Antidiabetic pharmacotherapy and insulin regimen}

Rather than focusing on glycemic control in elderly patients with T2DM, it is important to maintain quality of life and patients' ability to self-manage their diabetes. Current guidelines recommend simplifying treatment (eg, by using basal insulin and avoiding the additional use of regular and rapid-acting insulin) and to use drug classes with low hypoglycemic effect. ${ }^{13}$ 30-32 BOT was used three times more frequently in the BIA group compared with $\mathrm{HI} / \mathrm{NPH}(42.6 \%$ vs $14.4 \%)$ and the BIA

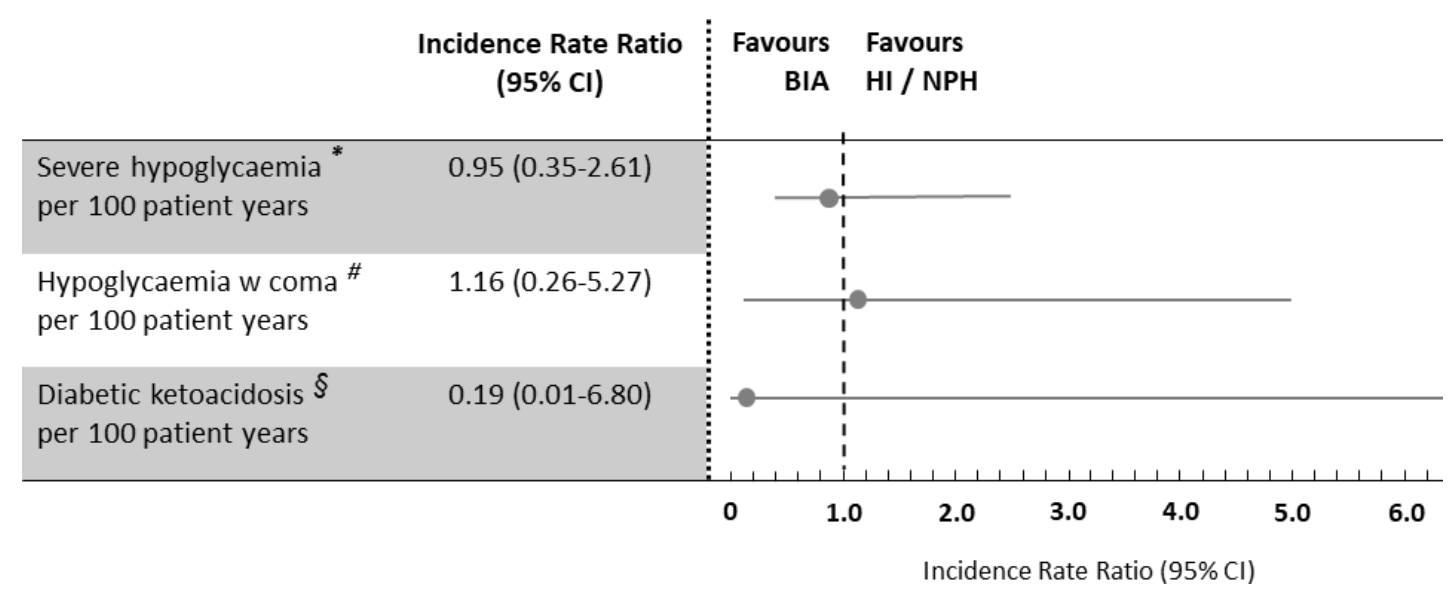

Figure 2 Incidence rate ratio. *Defined as an event requiring assistance by another person to actively administer carbohydrates, glucagon or other resuscitative actions. "Defined as loss of consciousness or occurrence of seizures. ${ }^{\S}$ Defined as $\mathrm{pH}<7.3$ and/or bicarbonate $<15 \mathrm{mmol} / \mathrm{mol}$ or hospitalization for diabetic ketoacidosis. BIA, basal insulin analogs; $\mathrm{HI}$, human insulin; NPH, neutral protamine Hagedorn. 
group needed lower total daily insulin levels. Further, in our study additional rapid-acting insulins were needed less often in the BIA group compared with the HI/ NPH group. Thus, data indicate that current guidelines advising a simple patient-approached therapy regimen to maintain self-management abilities in the elderly were better reflected by using a BOT regimen with insulin analogs. ${ }^{13}$

One study indicates a longer persistence on BOT therapy in elderly patients with T2DM with BIA before intensifying to ICT compared with patients with $\mathrm{NPH} .{ }^{33}$ Further, with BOT additional antidiabetic drugs are necessary, ${ }^{34}$ explaining the higher percentages of concomitant medication in the BIA group compared with $\mathrm{HI} / \mathrm{NPH}$.

In contrast to that, more than half of the HI/NPH group used a CT insulin regimen (56.2\%). CT necessitates fixed meal times and is useful in less active or care-dependent patients. ${ }^{34}$ It is likely that patients who have used this treatment strategy for long periods of time were not switched as they aged. In contrast to CT, the more complex ICT is used in active patients with T2DM with good mental and functional status but poor glycemic control. ${ }^{34}$ The higher proportion of ICT in the BIA group indicates that a higher proportion of patients had difficulty stabilizing their diabetes and explains the higher prandial to total insulin ratio. Another reason for the higher ICT proportion with BIA might be the higher risk of hypoglycemia with ICT and physicians might have prescribed BIA due to its promoted antihypoglycemic properties. Furthermore, the BIA group needed lower total daily insulin levels, but a higher percentage of patients were treated with newer non-insulin antidiabetic agents. For example, the proportion of DPP-4 inhibitors was twice as high compared with the HI/NPH group (10.0\% vs $25.8 \%$ ). In studies, DPP-4 inhibitors, GLP agonists and SGLT-2 inhibitors showed a reduced risk of hypoglycemia, and DPP-4 inhibitors are often used in elderly patients and in patients with renal impairment. ${ }^{34}$ However, GLP-1 agonists have to be injected and overall rates of GLP-1 agonists and SLGT-2 inhibitors were low $(<5 \%)$.

\section{Glycemic control and safety}

In older adults with few coexisting chronic illnesses and good mental and functional status, the glycemic target of HbAlc should be $<7.5 \%$. Multimorbid patients, however, should have less strict glycemic goals with HbAlc values between $8.0 \%$ and $8.5 \% .^{13} 243132$ In our study HbAlc decreased clinically relevant with insulin therapy to a mean follow-up HbAlc of $7.3 \%$ and $7.4 \%$, suggesting that there might still be a slight antiglycemic overtreatment in this elderly population at high risk of diabetic and cardiovascular complications. Antiglycemic overtreatment of older patients with T2DM has been shown to be common and the possibly resulting harm is cited in guidelines. ${ }^{31} 3435$

In our study, $2.8 \%$ and $2.4 \%$ of the patients were documented with severe hypoglycemia and the event rates per $100 \mathrm{PY}$ were low (HI/NPH 4.40 vs BIA 4.07) and even lower for hypoglycemia with coma (HI/NPH 3.26 vs BIA 3.64), tending toward lower rates with BIA, but without significant differences. There is no clear evidence of studies comparing the two insulin types with regard to the risk of hypoglycemic events. Studies in elderly patients are lacking and severe hypoglycemia is often unrecognized in elderly patients with T2DM. ${ }^{30}$ Most of the available studies in patients with T2DM show comparable effects for HbAlc and a lower risk for patients experiencing hypoglycemia for insulin analogs when compared with NPH insulin. ${ }^{36}$ However, results of recent studies comparing insulin analogs with premixed or split regular insulin regimens are incongruent with regard to the frequency and severity of hypoglycemia and the occurrence of nocturnal hypoglycemia. ${ }^{87-41}$ This was also true for rapid-acting analogs versus regular $\mathrm{HI} .{ }^{42} \mathrm{~A}$ recent observational study using Medicare claims data examined the association between long-acting insulin analog use and emergency department visits or hospitalizations for hypoglycemia in more than 575000 T2DM insulin users over 65 years. ${ }^{43}$ Bradley $e t a t^{43}$ showed that the initiation of glargine and detemir use was associated with a reduced risk of hypoglycemia compared with NPH insulin use (HR for glargine vs NPH 0.71, 95\% CI 0.63 to 0.80 ; HR for detemir vs NPH 0.72, $95 \%$ CI 0.63 to 0.82 ). The protective association was not seen with concomitant prandial insulin use. In a real-world setting as well as in our study long-acting insulin and prandial insulin are often used together. Therefore, potential benefits of BIA use in our study might not have been that clear. Overall, the split evidence evokes a controversial expert discussion about the clinically relevant differences of the two insulin types. ${ }^{3444}$

\section{Limitations}

The strength of this analysis is the large number of elderly patients aged $\geq 75$ years with a matched group comprising over 8000 patients in a real-world setting and a mean age of 80.3 years. However, in an observational study residual selection bias despite the effect of propensity score matching is possible, for example by the sole involvement of specialized diabetes centers in the DIVE/DPV registries. Newer concepts such as frailty and sarcopenia are rarely or not reported in the registries due to lack of consensus on diagnostic criteria; for example, International Classification of Diseases-10 for sarcopenia was only established in $2016 .^{32}{ }^{45}$ Furthermore, the analysis included follow-up data from 2000. This may lead to an under-representation of newer therapy options, such as non-insulin antidiabetic drugs (SGLT-2 inhibitors, GLP-1 agonists) and the use of insulin analogs. Finally, we did not distinguish between premixed and split usage of insulins, which might also have an implication on outcomes.

\section{CONCLUSIONS}

Compared with patients on regular insulins patients treated with insulin analogs used more flexible therapy regimens with overall lower doses of total daily insulin. The high percentage of BOT and the lower use of rapid-acting insulin in the BIA group reflect the current 
guidelines that recommend a simplified therapy in the elderly to maintain self-management abilities.

With regard to glycemic control, there might be a slight overtreatment in this elderly population with high proportions of macrovascular and microvascular diseases. Therapy goals, therefore, should be adapted continuously and individually to patients' needs. The risk of severe hypoglycemic events is low and comparable between the two insulin types in patients with T2DM aged $\geq 75$ years. However, further analyses of elderly patients are urgently needed to provide evidence for best practice medical care in this age group.

\section{Author affiliations}

${ }^{1}$ Institute for Pharmacology and Preventive Medicine, Cloppenburg, Germany ${ }^{2}$ Institute of Epidemiology and Medical Biometry, ZIBMT, University of UIm, Ulm, Germany

${ }^{3}$ German Center for Diabetes Research (DZD), München-Neuherberg, Germany ${ }^{4}$ Department of Internal Medicine, Knappschaftskrankenhaus Bottrop, Bottrop, Germany

${ }^{5}$ Center for Diabetes Ludwigsburg, Ludwigsburg, Germany

${ }^{6}$ Specialized Diabetes Practice Berlin Tempelhof, Berlin, Germany

${ }^{7}$ Medical Practice for Internal Medicine and Diabetology Rhein-Sieg, Niederkassel-

Rheidt, Germany

${ }^{8}$ Department of Internal Medicine I, Martin-Luther-University Halle-Wittenberg, University Medicine, Academic Hospital Paul-Gerhardt-Stift, Lutherstadt Wittenberg, Germany

${ }^{9}$ Medical Practice for Internal Medicine Rottweil, Rottweil, Germany

Acknowledgements We thank all participating centers of the DPV and DIVE initiatives.

Contributors RW, JG, SS, RB, PMJ and DE contributed to data collection. GvM, SRT and PB designed the analysis, drafted the manuscript and created the figures. SRT and SL were responsible for statistical analyses. SRT and SL contributed to discussion and reviewed the manuscript. GvM edited the manuscript. SRT and SL had full access to all the data in the study and take responsibility for the integrity of the data and the accuracy of the data analysis. All authors approved the final manuscript.

Funding Financial support of the DPV registry was provided by the European Foundation for the Study of Diabetes (EFSD). It was also supported by the German Center for Diabetes Research (DZD, grant number 82DZD14A02) and the German Diabetes Society (DDG). The DIVE registry was funded by Abbott, AstraZeneca, Bayer, Boehringer Ingelheim and Sanofi. Funders were not involved in the analysis and interpretation of data, writing of the manuscript or decision to submit the article for publication.

Competing interests $\mathrm{PB}$ reports to have received consultancy honoraria from Sanofi and Abbott.

Patient consent for publication Not required.

Ethics approval The DPV initiative, which was established in 1995, was approved by the ethics committee of the University of Ulm (no. 202-09 on August 14, 2009), and data collection was approved by local review boards. The DIVE registry was established in Germany in 2011. The protocol was approved by the ethics committee of the Medical School of Hannover (no. 6003 on August 25, 2011).

Provenance and peer review Not commissioned; externally peer reviewed.

Data availability statement Data are available upon reasonable request. Data may be obtained from a third party and are not publicly available. The data sets generated and analyzed during the current study are not publicly available due to data privacy but are available from the corresponding author on reasonable request.

Open access This is an open access article distributed in accordance with the Creative Commons Attribution Non Commercial (CC BY-NC 4.0) license, which permits others to distribute, remix, adapt, build upon this work noncommercially, and license their derivative works on different terms, provided the original work is properly cited, appropriate credit is given, any changes made indicated, and the use is non-commercial. See: http://creativecommons.org/ licenses/by-nc/4.0/.

ORCID iD

Peter Bramlage http://orcid.org/0000-0003-4970-2110

\section{REFERENCES}

1 Hartmann B, Lanzinger S, van Mark G, et al. Treatment intensification strategies after initial metformin therapy in adult patients with type-2 diabetes: results of the DPV and dive registries. Acta Diabetol 2020;57:229-36.

2 van Mark G, Tittel SR, Sziegoleit S, et al. Type 2 diabetes in older patients: an analysis of the DPV and DIVE databases. Ther Adv Endocrinol Metab 2020;11:204201882095829.

3 Lipska KJ, Ross JS, Wang Y, et al. National trends in US hospital admissions for hyperglycemia and hypoglycemia among Medicare beneficiaries, 1999 to 2011. JAMA Intern Med 2014;174:1116-24.

4 Bramlage P, Gitt AK, Binz C, et al. Oral antidiabetic treatment in type-2 diabetes in the elderly: balancing the need for glucose control and the risk of hypoglycemia. Cardiovasc Diabetol 2012;11:122.

5 Cheng AYY, Wong J, Freemantle N, et al. The safety and efficacy of second-generation basal insulin analogues in adults with type 2 diabetes at risk of hypoglycemia and use in other special populations: a narrative review. Diabetes Ther 2020;11:2555-93.

6 Davies MJ, D'Alessio DA, Fradkin J, et al. Management of hyperglycemia in type 2 diabetes, 2018. A consensus report by the American diabetes association (ADA) and the European association for the study of diabetes (EASD). Diabetes Care 2018;41:2669-701.

7 Monami M, Marchionni N, Mannucci E. Long-Acting insulin analogues versus NPH human insulin in type 2 diabetes: a metaanalysis. Diabetes Res Clin Pract 2008;81:184-9.

8 Ritzel R, Roussel R, Bolli GB, et al. Patient-Level meta-analysis of the edition 1,2 and 3 studies: glycaemic control and hypoglycaemia with new insulin glargine $300 \mathrm{U} / \mathrm{ml}$ versus Glargine $100 \mathrm{U} / \mathrm{ml}$ in people with type 2 diabetes. Diabetes Obes Metab 2015;17:859-67.

9 Lajara R, Cengiz E, Tanenberg RJ. The role of the new basal insulin analogs in addressing unmet clinical needs in people with type 1 and type 2 diabetes. Curr Med Res Opin 2017;33:1045-55.

10 Bohn B, Kerner W, Seufert J, et al. Trend of antihyperglycaemic therapy and glycaemic control in 184,864 adults with type 1 or 2 diabetes between 2002 and 2014: analysis of real-life data from the DPV registry from Germany and Austria. Diabetes Res Clin Pract 2016;115:31-8.

11 Schwab KO, Doerfer J, Hungele A, et al. Non-High-Density lipoprotein cholesterol in children with diabetes: proposed treatment recommendations based on glycemic control, body mass index, age, sex, and generally accepted cut points. $J$ Pediatr 2015;167:1436-9.

12 Danne T, Kaltheuner M, Koch A, et al. ["Dlabetes VersorgungsEvaluation" (DIVE)--a national quality assurance initiative at physicians providing care for patients with diabetes]. Dtsch Med Wochenschr 2013;138:934-9.

13 S2k-Leitlinie Diagnostik, therapie und Verlaufskontrolle des diabetes mellitus Im alter. AWMF-Registernummer: 057-017. Available: https://www.deutsche-diabetes-gesellschaft.de/fileadmin/ Redakteur/Leitlinien/Evidenzbasierte_Leitlinien/2018/057_017_LL Alter_Gesamtdokument_20180713.pdf [Accessed 18 Jan 2021].

14 Recommendations for managing type 2 diabetes in primary care. Available: www.idf.org/managing-type2-diabetes [Accessed 4 October 2020].

15 Cosentino F, Grant PJ, Aboyans V, et al. 2019 ESC guidelines on diabetes, pre-diabetes, and cardiovascular diseases developed in collaboration with the EASD. Eur Heart $J$ 2020;41:255-323.

16 Masnoon N, Shakib S, Kalisch-Ellett L, et al. What is polypharmacy? A systematic review of definitions. BMC Geriatr 2017;17:230.

17 Holt S, Schmiedl S, Thürmann PA. Potentially inappropriate medications in the elderly: the PRISCUS list. Dtsch Arztebl Int 2010;107:543-51.

18 DCCT Research Group. Diabetes control and complications trial (DCCT). Update. DCCT Research Group. Diabetes care 1990;13:427-33.

19 DCCT Research Group. Feasibility of centralized measurements of glycated hemoglobin in the diabetes control and complications trial: a multicenter study. The DCCT Research Group. Clin Chem 1987;33:2267-71.

20 Workgroup on Hypoglycemia, American Diabetes Association. Defining and reporting hypoglycemia in diabetes: a report from the American diabetes association Workgroup on hypoglycemia. Diabetes Care 2005;28:1245-9. 
21 Karges B, Schwandt A, Heidtmann B, et al. Association of insulin pump therapy vs insulin injection therapy with severe hypoglycemia, ketoacidosis, and glycemic control among children, adolescents, and young adults with type 1 diabetes. JAMA 2017;318:1358-66.

22 Austin PC. An introduction to propensity score methods for reducing the effects of confounding in observational studies. Multivariate Behav Res 2011;46:399-424.

23 Bramlage P, Lanzinger S, Rathmann W, et al. Dyslipidaemia and its treatment in patients with type 2 diabetes: a joint analysis of the German DIVE and DPV registries. Diabetes Obes Metab 2017;19:61-9.

24 LeRoith D, Biessels GJ, Braithwaite SS, et al. Treatment of diabetes in older adults: an endocrine Society* clinical practice guideline. $J$ Clin Endocrinol Metab 2019;104:1520-74.

25 Sevilla-González MDR, Quintana-Mendoza BM, Aguilar-Salinas CA. Interaction between depression, obesity, and type 2 diabetes: a complex picture. Arch Med Res 2017;48:582-91.

26 Climie RE, van Sloten TT, Bruno R-M, et al. Macrovasculature and microvasculature at the crossroads between type 2 diabetes mellitus and hypertension. Hypertension 2019;73:1138-49.

27 Nadash P, Doty P, von Schwanenflügel M. The German long-term care insurance program: evolution and recent developments. Gerontologist 2018;58:588-97.

28 Deutschlandergebnisse. Statistisches Bundesamt: Pflegestatistik, 2019. Available: https://www.destatis.de/DE/Themen/GesellschaftUmwelt/Gesundheit/Pflege/Publikationen/Downloads-Pflege/pflegedeutschlandergebnisse-5224001199004.pdf? blob=publicationFile [Accessed 18 Jan 2021].

29 Hodeck K, Tittel SR, Dreyhaupt I. Charakteristika von Diabetespatienten mit und ohne Pflegebedürftigkeit. Diabetologie und Stoffwechsel 2020;15:392-9.

30 Cersosimo E, Lee PG, Pandya N. Challenges of diabetes care in older people with type 2 diabetes and the role of basal insulin. Clin Diabetes 2019;37:357-67.

31 American Diabetes Association. 12. Older Adults: Standards of Medical Care in Diabetes-2021. Diabetes Care 2021;44:S168-79.

32 Strain WD, Hope SV, Green A, et al. Type 2 diabetes mellitus in older people: a brief statement of key principles of modern day management including the assessment of frailty. A national collaborative stakeholder initiative. Diabet Med 2018;35:838-45.

33 Pscherer S, Chou E, Dippel F-W, et al. Treatment persistence after initiating basal insulin in type 2 diabetes patients: a primary care database analysis. Prim Care Diabetes 2015;9:377-84.
34 Nationale Versorgungsleitlinie Typ-2-Diabetes, Langfassung, 2. Auflage, Konsultationsfassung. Available: https://www.leitlinien.de/ $\mathrm{mdb} /$ downloads/nvl/diabetes-mellitus/dm-2aufl-konsultation.pdf [Accessed 23 Jan 2021].

35 Lipska KJ, Krumholz H, Soones T, et al. Polypharmacy in the aging patient: a review of glycemic control in older adults with type 2 diabetes. JAMA 2016:315:1034-45.

36 Semlitsch T, Engler J, Siebenhofer A, et al. (Ultra-)long-acting insulin analogues versus NPH insulin (human isophane insulin) for adults with type 2 diabetes mellitus. Cochrane Database Syst Rev 2020;11:CD005613.

37 Umpierrez GE, Hor T, Smiley D, et al. Comparison of inpatient insulin regimens with detemir plus aspart versus neutral protamine Hagedorn plus regular in medical patients with type 2 diabetes. $J$ Clin Endocrinol Metab 2009:94:564-9.

38 Liebl A, Prager R, Binz K, et al. Comparison of insulin analogue regimens in people with type 2 diabetes mellitus in the PREFER study: a randomized controlled trial. Diabetes Obes Metab 2009;11:45-52.

39 Fritsche A, Larbig M, Owens D, et al. Comparison between a basal-bolus and a premixed insulin regimen in individuals with type 2 diabetes-results of the ginger study. Diabetes Obes Metab 2010;12:115-23.

40 Bowering K, Reed VA, Felicio JS, et al. A study comparing insulin lispro mix 25 with glargine plus lispro therapy in patients with type 2 diabetes who have inadequate glycaemic control on oral antihyperglycaemic medication: results of the PARADIGM study. Diabet Med 2012;29:e263-72.

41 Luo J, Khan NF, Manetti T, et al. Implementation of a health plan program for switching from analogue to human insulin and glycemic control among Medicare beneficiaries with type 2 diabetes. JAMA 2019:321:374-84.

42 Fullerton B, Siebenhofer A, Jeitler K, et al. Short-Acting insulin analogues versus regular human insulin for adult, non-pregnant persons with type 2 diabetes mellitus. Cochrane Database Syst Rev 2018;12:CD013228.

43 Bradley MC, Chillarige $\mathrm{Y}$, Lee $\mathrm{H}$, et al. Severe hypoglycemia risk with long-acting insulin analogs vs neutral protamine Hagedorn insulin. JAMA Intern Med 2021;181:598-607.

44 Davidson MB. The case for using human insulin. Am J Med 2020;133:e23-4.

45 Cruz-Jentoft AJ, Bahat G, Bauer J, et al. Sarcopenia: revised European consensus on definition and diagnosis. Age Ageing 2019;48:16-31. 